\title{
Sexual polymorphisms in Narcissus triandrus (Amaryllidaceae): is this species tristylous?
}

\author{
SPENCER C. H. BARRETT*, WILLIAM W. COLE, JUAN ARROYO + , MITCHELL B. \\ CRUZAN $¥$ \& DAVID G. LLOYD§ \\ Department of Botany, University of Toronto, Toronto, Ontario, Canada M5S 3B2, +Departamento de Biología \\ Vegetal y Ecología, University of Seville, 41080 Seville, Spain, $\ddagger$ Department of Botany, University of Tennessee, \\ Knoxville, TN 37996-1100, U.S.A. and §Department of Plant and Microbial Sciences, University of Canterbury, \\ Christchurch 1, New Zealand
}

\begin{abstract}
The sexual polymorphism tristyly is well documented in three flowering plant families (Lythraceae, Oxalidaceae and Pontederiaceae). Controversy has arisen as to whether the polymorphism exists in Narcissus triandrus L. of the Amaryllidaceae. Surveys of floral variation in 80 populations in Spain and Portugal were undertaken to determine the nature of sexual polymorphisms in the species. Most populations ( 85 per cent) contained three discrete floral morphs that differ from one another in the sequence in which the stigma and the two anther levels within a flower are presented. Hence, the species is genuinely tristylous. Floral morph frequencies deviated strongly from the isoplethic expectations (1:1:1) typical of tristylous species. Average frequencies for the morphs were $\mathrm{L}$ morph $=0.59, \mathrm{M}$ morph $=0.19$ and $\mathrm{S}$ morph $=0.22$. In 15 per cent of the populations sampled, the mid-styled morph was absent. Controlled crosses indicated that individuals are moderately self-sterile but cross-compatible with other individuals, regardless of morph. Therefore, the species does not possess a conventional heteromorphic incompatibility system. Self-sterility operates in the ovary, and prior selfpollination of flowers renders ovules nonfunctional as judged by reduced seed-set in subsequent cross-pollinations. Multilocus outcrossing estimates in four tristylous populations averaged $t=0.77$, range $0.68-0.87$, with significant variation evident among morphs but not populations. All population estimates were less than 1 , indicating significant amounts of selfing. Although $N$. triandrus is clearly tristylous, the expression of the polymorphism is unique among tristylous families.
\end{abstract}

Keywords: late-acting self-sterility, Narcissus triandrus, outcrossing rates, sexual polymorphism, tristyly.

\section{Introduction}

Self-incompatible flowering plants have traditionally been divided into two major categories, depending on whether or not mating types are morphologically identical (Nettancourt, 1977; Barrett, 1988). In species with homomorphic incompatibility, populations are composed of many morphologically indistinguishable mating types, whereas in those exhibiting heteromorphic incompatibility either two (distyly) or three (tristyly) self- and intramorphincompatible mating groups usually occur. The rarer form of heteromorphic incompatibility is tristyly. In populations of tristylous plants, there are three floral

*Correspondence. E-mail: barrett@botany.utoronto.ca

(C) 1997 The Genetical Society of Great Britain. forms - the long-, mid- and short-styled morphs (hereafter called L, M and S morphs respectively) which differ reciprocally in the heights at which stigmas and anthers are positioned within flowers. This genetic polymorphism is well documented in eight genera occurring in three unrelated angiosperm families: the Lythraceae, Oxalidaceae and Pontederiaceae (reviewed in Barrett, 1993). Recent evidence also indicates that the polymorphism occurs in tropical taxa in the Connaraceae (Lemmens, 1989), Linaceae (Thompson et al., 1996) and, possibly, the Thymelaeaceae (Zavada \& Lowrey, 1995).

An historical controversy exists as to whether tristyly occurs in the monocotyledonous genus Narcissus of the Amaryllidaceae (reviewed in Barrett 
et al., 1996). Several early European workers reported heterostyly in the genus, particularly in Narcissus triandrus (e.g. Henriques, 1887; Fernandes, 1935,1965 ), a common spring-flowering bulb from Spain and Portugal that has also been cultivated widely as an ornamental (Blanchard, 1990). However, the occurrence of tristyly was later disputed by Bateman (1952), based on his own experimental studies on a limited number of bulbs sent to him by the Portuguese botanist Abílio Fernandes. Modern workers studying heterostyly accepted Bateman's view and, as a result, recent reviews of heterostyly either have not recognized tristyly in Narcissus or have discussed the variation patterns in the genus as cases of anomalous floral heteromorphisms fundamentally distinct from heterostyly.

In a recent reappraisal of the Narcissus controversy, Lloyd et al. (1990) reconsidered the evidence presented in earlier papers and, in addition, examined patterns of style length and stamen height in five horticultural cultivars of $N$. triandrus grown in New Zealand. They concluded that the weight of evidence favours the opinions of Henriques and Fernandes that tristyly occurs in $N$. triandrus but that further work, particularly field studies in Spain and Portugal, would be desirable. In an effort to resolve the issue of whether $N$. triandrus is fully tristylous, we have conducted field surveys and experimental studies on this species. In this paper, we address the following specific questions. (i) Are the three floral morphs that characterize tristylous species present in natural populations of $N$. triandrus and do they occur at the 1:1:1 frequencies expected for tristylous populations at equilibrium? (ii) What are the compatibility relationships of the floral morphs and does the species possess a conventional heteromorphic incompatibility system? (iii) What type of selfsterility system operates in N. triandrus? (iv) What are the patterns of mating in natural populations and do the floral morphs differ in outcrossing rate? Here, we present the results of this work and discuss their implications for the pollination biology and mating systems of populations.

\section{Materials and methods}

\section{Survey of natural populations}

Narcissus triandrus is widespread and common in central and northern regions of the Iberian Peninsula. In March-April 1990 and 1991, during peak flowering, we surveyed a total of 80 populations from throughout the native range of the species, including southern, central and northern Spain and central and northern Portugal. Detailed localities of all populations are available from the senior author on request. For sampling, we adopted a broad species concept for $N$. triandrus, including taxa that have been recognized at both the intra- and interspecific levels (e.g. N. triandrus vars. triandrus, cernuus, concolor, loiseleurii; see Blanchard, 1990). In each population, a random sample of flowering stems was obtained and each stem was classified according to style morph (see below). In selected populations, quantitative floral measurements of variation in style length and anther height were obtained from randomly sampled stems. The position of sex organs in each flower was measured relative to the top of the ovary, because ovary size increases during anthesis if flowers are pollinated.

\section{Experimental pollinations}

Patterns of seed set To investigate whether $N$. triandrus possesses a heteromorphic incompatibility system, experimental pollinations were conducted in the glasshouse on plants transplanted from natural populations. In April 1991, several hundred bulbs were removed before flowering from a large population (population 79) containing several thousand plants located $3 \mathrm{~km}$ north of the town of El Hoyo de Pinares-1, Avila province, central Spain. During the next month, 284 controlled hand pollinations were conducted under glasshouse conditions at an average temperature of $15-25^{\circ} \mathrm{C}$. In April 1992, an additional 175 hand pollinations were also conducted on plants overwintered in the glasshouse to confirm the results obtained from the previous year. Seventy-four per cent of the plants in these pollinations were the same as those used in 1991 (population 79), but also involved material obtained from an additional seven populations from other localities in Spain (populations 1, 14, 19, 28, 31, 73 and 76).

A total of 180 plants ( 60 per floral morph) were used in the pollination experiment. Plants were selfed (self) or crossed to the same morph as the female parent (intramorph) or to an alternative morph (intermorph). Pollen originating from the two anther levels within a morph was contrasted for each of the three classes of cross. If $N$. triandrus has a trimorphic incompatibility system, only crosses between stigmas and anthers of equivalent height (legitimate pollination) would yield full seed-set. The remaining self, intramorph and intermorph pollinations (illegitimate pollinations) would give little or no seed-set. Pollinations were conducted using fine forceps during the first 3 days of the 7-10-day anthesis period using a single anther from 
each pollen donor. After 5-6 weeks, when capsules were mature, they were harvested individually and the contents divided into three categories based on their size and colour, and counted using a Zeiss binocular dissecting microscope. Mature seeds were plump, filled and black, aborted seeds were smaller, shrunken and black, and undeveloped or very early aborting ovules (hereafter termed undeveloped) were small, flake-like and white or pale brown.

Data from experimental pollinations were analysed by ANOVA using the GLM procedure of SAS (SAS, 1988). Three main effects on variation in the number of mature seeds, aborted seeds and undeveloped ovules were examined. These were floral morph, pollination treatment and number of pollen tubes at the base of the style (see below). The specific pollination treatments contrasted were self vs. outcross and intramorph vs. intermorph crosspollination. To investigate the effect of anther level on variation in seed set, a modification of the above design was used in which anther level was nested within floral morph and pollination treatment. This involved the use of a completely randomized partial hierarchical design.

Pollen tube growth Pollen tube growth following controlled self- and cross-pollinations was investigated on plants used in the 1991 pollination programme described above. The number of pollen tubes at the base of the style (PTB, see below) was counted for the various classes of pollination. Styles were harvested 7 days after pollination and fixed in 70 per cent alcohol. Styles were cleared with $8 \mathrm{~N}$ sodium hydroxide at $60^{\circ} \mathrm{C}$ for $1 \mathrm{~h}$. Cleared styles were rinsed with water three times then stained with 0.1 per cent aniline blue in $0.6 \mathrm{M}$ Tris $-\mathrm{HCl}$ buffer ( $\mathrm{pH} 7.0$ ) for at least $24 \mathrm{~h}$. The number of pollen grains on the stigma and pollen tubes at the base of the style was recorded using a fluorescence microscope (Zeiss Axioplan $365 \mathrm{~nm}$ excitation and 420 barrier filters).

Effects of prior self-pollination on outcrossed seedset To investigate the effects of prior self-pollination on the seed-set of cross-pollinated flowers, two experimental pollinations were conducted on plants from population 79 under glasshouse conditions in 1991. On 36 two-flowered plants (12 per floral morph), one flower was self-pollinated followed $24 \mathrm{~h}$ later by cross-pollination, and the other flower was cross-pollinated only. Both flowers on a given plant were cross-pollinated on the same day and the two treatments were randomized among plants with respect to floral position (basal or distal), because of potential position effects on ovule number and seed-set. Mature fruit were collected individually and the contents classified and counted as described above.

\section{Analysis of mating patterns in natural populations}

Estimates of outcrossing frequency Allozyme polymorphisms at three loci [aspartate aminotransferase $(A A T-2)$, phosphoglucoisomerase $(P G I-1)$ and phosphoglucomutase $(P G M-1)]$ detected in seed extracts were used to estimate the outcrossing frequency of floral morphs in four populations of $N$. triandrus. Open-pollinated seed families were collected separately from the three floral morphs in 1991. Seeds were ground in Plexiglas blocks in a DL-dithiothreitol extraction buffer and the extract adsorbed onto filter paper wicks and run on 11 per cent starch gels (discontinuous lithium borate gel, $\mathrm{pH} 8.3)$. Single- and multilocus outcrossing rates $\left(t_{\mathrm{s}}\right.$ and $t_{\mathrm{m}}$, respectively) were estimated using the maximum likelihood method of Ritland (computer program MLT; Ritland, 1990). Standard errors of the estimates were derived as the standard deviation of 1000 bootstrap values with the progeny array as the unit of resampling.

Differences in outcrossing rate among populations and floral morphs were assessed using pairwise comparisons of 1000 bootstrap estimates and also by ANOVA. In the first approach, two populations or morphs were considered to differ significantly if $100\left(1-\alpha_{\mathrm{PC}} / 2\right)$ per cent of the differences between the randomly paired bootstrap estimates lay either all above or all below zero (where $\alpha_{\mathrm{pC}}$ is the Type I error rate per contrast). The experimentwise error rate $\left(\alpha_{\mathrm{EW}}\right)$ was held at 0.05 using Sidák's (1967) correction for nonorthogonal contrasts. Comparisons of outcrossing rate by ANOVA involved a two-way ANOVA with population and morph considered as fixed effects and $t$ estimates weighted by the inverse of their squared standard errors to take account of sampling errors associated with the estimates.

\section{Results}

\section{Floral variation in natural populations}

Surveys of sex-organ polymorphism in most natural populations of $N$. triandrus revealed the presence of three distinct floral morphs differing in the sequence in which stigmas and anthers are presented within flowers (Fig. 1). The floral morphs possess long, mid or short styles that differ significantly in length and 
Pop. 2

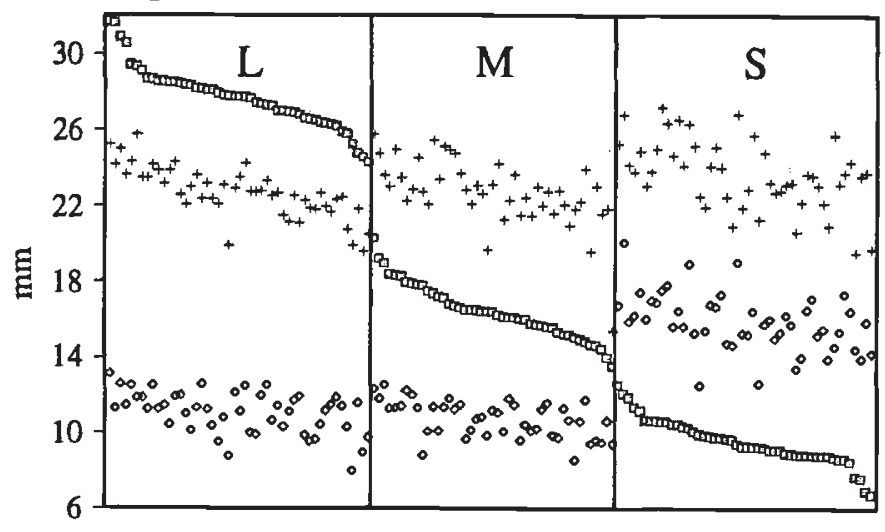

Pop. 31

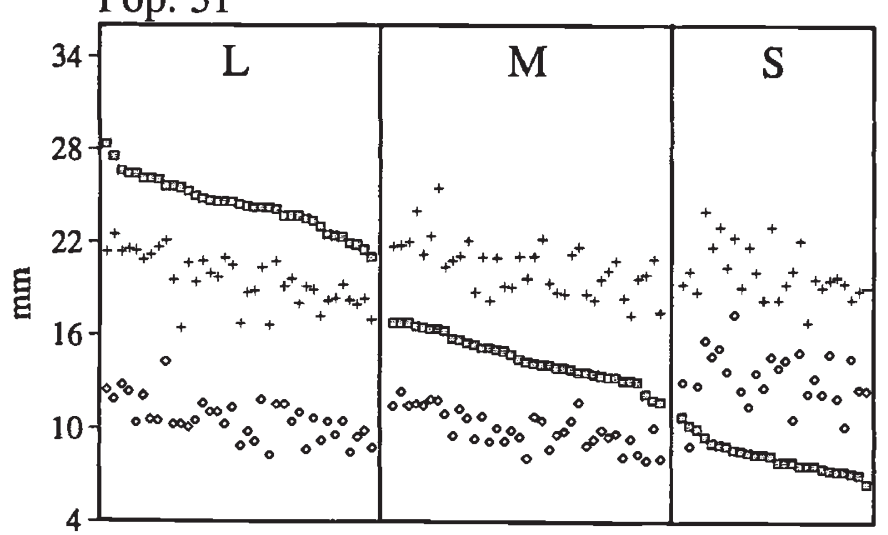

Pop. 15

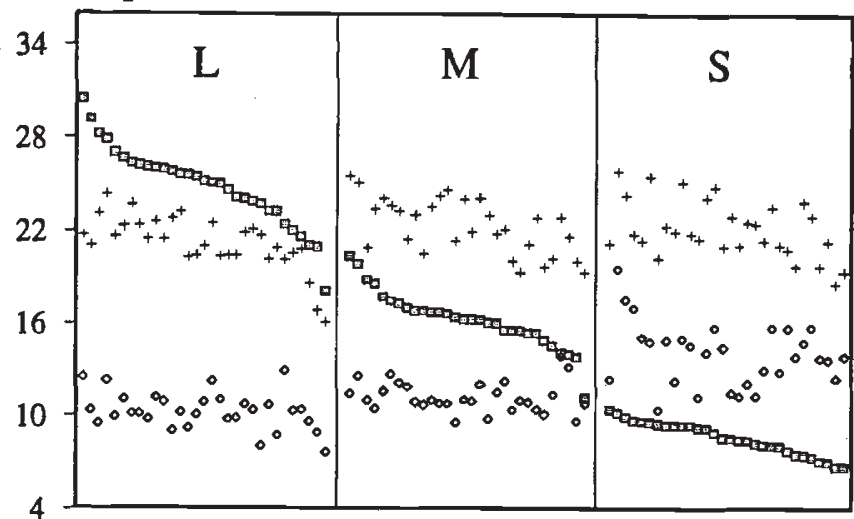

Pop. 72

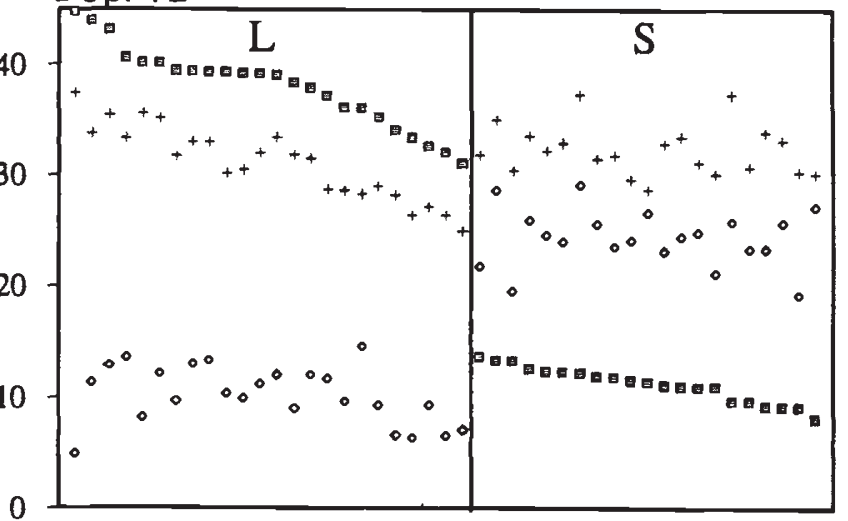

Fig. 1 Variation in the height of female and male sexual organs in four populations of Narcissus triandrus (style length $\square$, upper anthers + , lower anthers $\diamond$ ). Individuals in each population are ordered by decreasing style length. Each anther height is the mean of the three anthers per level. Note that, in trimorphic populations, three distinct morphs are evident differing in the sequence in which anthers and stigmas are presented. Unlike most tristylous species, anther heights are similar in the $\mathrm{L}$ and $\mathrm{M}$ morphs. In the dimorphic population, the $\mathrm{M}$ morph is missing. Popuiations 2,15 and 31 are trimorphic and population 72 is dimorphic for style length. Localities for the populations are 2 - Calera de León-1, Badajoz province, Spain; 15 - El Raso-1, Avila province, Spain; 31 - Alvares, Beria Litoral province, Portugal; 72 Cedeira-1, La Coruña province, Spain.

two distinct anther levels within each flower. In the $\mathrm{L}$ morph, stigmas are positioned above the two anther levels; in the $\mathrm{M}$ morph, stigmas are located between the upper and lower anthers; and in the S morph, stigmas are below mid- and long-level anthers. Three anther levels are evident that correspond in height to stigmas of the long-, mid- and short-styled morphs. Two anomalies are evident in the $\mathrm{L}$ morph in comparison with other tristylous species. In this morph, 'mid-level' anthers are positioned above stigmas of the $\mathrm{M}$ morph and mid-level anthers of the $\mathrm{S}$ morph. Hence, the two anther heights in the $\mathrm{L}$ and $\mathrm{M}$ morphs are similar in position. Secondly, on average, stigmas of the $\mathrm{L}$ morph are positioned above long-level anthers of the $M$ and $\mathrm{S}$ morph (Fig. 1). These patterns were evident in all populations and appear to be a general feature of the tristylous syndrome of $N$. triandrus.

The mean distance separating stigmas and the nearest anther was largest in the $S$ morph (stigmaanther separation in mm: L morph, $\bar{x}=2.59 ; \mathrm{M}$ morph, $\bar{x}=2.60$; S morph, $\bar{x}=4.65$ ), with the $\mathrm{L}$ and $\mathrm{M}$ morphs not significantly different (Bonferroni $t$ groupings). Stigma-anther separation also varied among populations. The interaction between morph and population was significant $\left(F_{6,456}=20.06\right.$, $P<0.001)$ in a two-way ANOVA of stigma-anther separation. In some populations, individuals with stigmas and anthers of a similar height occurred, particularly in the $\mathrm{L}$ morph. These individuals have been previously referred to as homostylous by Fernandes (1965). 
Among the 80 populations of $N$. triandrus that were surveyed, 85 per cent were trimorphic and 15 per cent were dimorphic. Data on style-morph frequencies within each of the 80 populations are

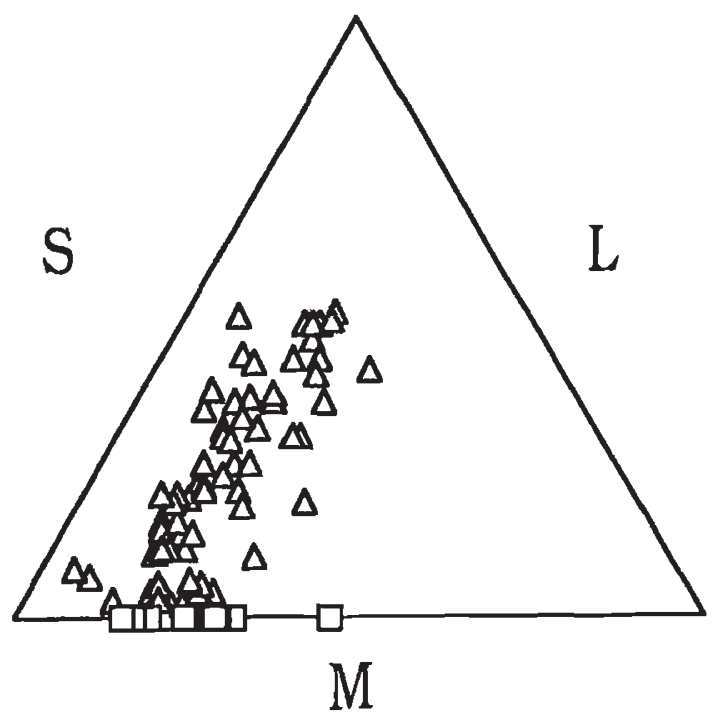

Fig. 2 Style morph frequencies in 80 populations of Narcissus triandrus from Spain and Portugal $(\triangle$ trimorphic, $\square$ dimorphic populations). Each population is represented by a single symbol positioned according to the morph frequencies in the population. The distance of a symbol to a given axis of the triangle is proportional to the frequency of a morph in that population. A hypothetical population with equal morph frequencies would be equidistant from all axes. plotted in Fig. 2. Two distinct patterns are evident. First, among trimorphic populations, the L morph predominated with the average frequencies of the $M$ and $S$ morphs similar (mean frequencies: $L$ morph $=0.57, \mathrm{M}$ morph $=0.22, \mathrm{~S}$ morph $=0.21$; $n=68$ populations and 14515 plants). Secondly, all dimorphic populations were missing the $M$ morph and, in common with trimorphic populations, the $\mathrm{L}$ morph predominated (mean frequencies: L morph $=0.71, \mathrm{~S}$ morph $=0.29 ; n=12$ populations and 1535 plants).

\section{Compatibility relationships and patterns of seed-set}

Patterns of fruit and seed-set following experimental hand pollination allow clear rejection of the hypothesis that $N$. triandrus possesses a heteromorphic incompatibility system (Table 1). Self-pollinations resulted in uniformly low levels of seed-set, whereas intramorph and intermorph pollinations produced abundant seed with similar amounts being produced from each pollination type. There were no significant differences between: (i) intramorph and intermorph pollinations (see contrast in Table 2); (ii) pollen originating from different anther levels $\left(F_{11,122}=0.42, P=0.946, F\right.$-value from an ANOVA identical to that in Table 2, with the addition of anther level nested within morph and pollination treatment); or (iii) floral morphs (Table 2).

Although the productivity of self-pollinations was significantly lower than intramorph and intermorph

Table 1 Mean seed-set of controlled hand pollinations conducted on Narcissus triandrus plants under glasshouse conditions

\begin{tabular}{|c|c|c|c|c|c|c|c|c|c|c|c|}
\hline \multirow{2}{*}{$\begin{array}{l}\text { Pollination } \\
\text { type }\end{array}$} & \multicolumn{3}{|c|}{ Long } & & \multicolumn{3}{|c|}{ Mid } & & \multicolumn{3}{|c|}{ Short } \\
\hline & $n$ & Mean & SE & & $n$ & Mean & SE & & $n$ & Mean & $\mathrm{SE}$ \\
\hline \multicolumn{12}{|l|}{ Legitimate } \\
\hline \multicolumn{12}{|l|}{ Intermorph } \\
\hline $\mathrm{L} \times \mathrm{l} / \mathrm{M}$ & 6 & 28.3 & 9.5 & $\mathrm{M} \times \mathrm{m} / \mathrm{L}$ & 4 & 30.3 & 4.8 & $\mathrm{~S} \times \mathrm{s} / \mathrm{L}$ & 5 & 42.6 & 5.2 \\
\hline $\mathbf{L} \times 1 / \mathbf{S}$ & 5 & 32.8 & 5.6 & $\mathrm{M} \times \mathrm{m} / \mathrm{S}$ & 5 & 39.8 & 12.0 & $\mathrm{~S} \times \mathrm{s} / \mathrm{M}$ & 5 & 35.2 & 7.0 \\
\hline \multicolumn{12}{|l|}{ Illegitimate } \\
\hline \multicolumn{12}{|l|}{ Self } \\
\hline $\mathrm{L} \times \mathrm{l} / \mathrm{L}$ & 15 & 5.8 & 1.1 & $\mathrm{M} \times \mathrm{l} / \mathrm{M}$ & 17 & 6.7 & 1.7 & $\mathrm{~S} \times \mathrm{l} / \mathrm{S}$ & 16 & 7.6 & 1.1 \\
\hline $\mathrm{L} \times \mathrm{s} / \mathrm{L}$ & 15 & 4.5 & 1.0 & $\mathrm{M} \times \mathrm{s} / \mathrm{M}$ & 18 & 4.8 & 1.2 & $\mathrm{~S} \times \mathrm{m} / \mathrm{S}$ & 15 & 6.0 & 1.6 \\
\hline \multicolumn{12}{|l|}{ Intramorph } \\
\hline $\mathrm{L} \times \mathrm{m} / \mathrm{L}$ & 5 & 45.4 & 5.8 & $\mathrm{M} \times \mathrm{l} / \mathrm{M}$ & 5 & 36.8 & 5.3 & $\mathrm{~S} \times \mathbf{1} / \mathrm{S}$ & 5 & 27.2 & 8.9 \\
\hline $\mathrm{L} \times \mathrm{s} / \mathrm{L}$ & 5 & 33.8 & 6.5 & $\mathrm{M} \times \mathrm{s} / \mathrm{M}$ & 5 & 39.8 & 9.4 & $\mathrm{~S} \times \mathrm{m} / \mathrm{S}$ & 5 & 30.0 & 4.0 \\
\hline \multicolumn{12}{|l|}{ Intermorph } \\
\hline $\mathrm{L} \times \mathrm{m} / \mathrm{S}$ & 5 & 42.4 & 4.11 & $M \times 1 / S$ & 5 & 37.6 & 6.9 & $\mathrm{~S} \times \mathrm{l} / \mathrm{M}$ & 5 & 43.8 & 10.0 \\
\hline $\mathbf{L} \times \mathbf{s} / \mathbf{M}$ & 6 & 30.2 & 5.7 & $\mathbf{M} \times \mathrm{s} / \mathrm{L}$ & 5 & 39.4 & 11.5 & $\mathrm{~S} \times \mathrm{m} / \mathrm{L}$ & 5 & 33.8 & 8.9 \\
\hline
\end{tabular}

Pollination types vary according to the style morph (upper-case) and anther level (lower-case) used in the pollinations. 
Table 2 Three-way anova of seed-set data from the controlled pollination experiment on Narcissus triandrus

\begin{tabular}{lrrrl}
\hline Source & d.f. & \multicolumn{1}{c}{ MS } & \multicolumn{1}{c}{$F$} & \multicolumn{1}{c}{$P$} \\
\hline Main effects & & & & \\
$\quad$ Morph & 2 & 16.89 & 0.11 & 0.8971 \\
$\quad$ PTB & 1 & 3033.46 & 19.52 & $0.0001^{* * *}$ \\
$\quad$ Pollination treatment & 2 & 748.50 & 4.82 & $0.0095^{* *}$ \\
$\quad$ Interactions & & & & \\
$\quad$ Morph $\times$ pollination treatment & 6 & 284.23 & 1.83 & 0.1268 \\
$\quad$ PTB $\times$ pollination treatment & 2 & 911.99 & 5.87 & $0.0036^{* *}$ \\
$\quad$ Contrasts & 1 & 1496.81 & 9.63 & $0.0023^{* *}$ \\
$\quad$ Self vs. cross & 1 & 86.36 & 0.56 & 0.4573 \\
$\quad$ Inter- vs. intramorph cross & 1 & & &
\end{tabular}

PTB, pollen tubes at the base of the style.

pollinations, the majority of self-pollinations yielded some mature seed (self: fruit-set 78 per cent, $\bar{x}=5.9$ seeds per pollination, $n=96$; intramorph: fruit-set 97 per cent, $\bar{x}=35.5$ seeds per pollination, $n=30$; intermorph: fruit-set 97 per cent, $\bar{x}=36.2$ seeds per pollination, $n=61$ ). A striking feature of the data involving cross-pollinations of $N$. triandrus was the wide variation in seed-set (range of seeds per fruit 0-78 for intramorph and 0-68 for intermorph). Near-continuous variation in seed-set values was evident for cross-pollinations conducted in both years (Fig. 3). In contrast, data on selfed seed-sets were narrowly distributed, with very few individuals showing moderate seed-set and none that was highly self-fertile.

Classification of fruit contents into mature seeds, aborted seeds and undeveloped ovules following self-pollination and intramorph and intermorph pollinations revealed significant differences among the pollination treatments for mature seeds and undeveloped ovules. Self-pollinations yielded significantly lower numbers of mature seeds than the two cross-pollination treatments (Table 1), whereas the reverse pattern was evident for undeveloped ovules $\left(F_{23,122}=7.02\right.$; mean undeveloped ovules: self $\bar{x}=59.25, n=93 ; \quad$ intramorph $\bar{x}=24.07, \quad n=30$; intermorph $\bar{x}=25.98, n=61$ ). In contrast, there were no significant differences in the number of aborted seeds per fruit following the three pollination treatments $\left(F_{23,122}=0.96\right.$; mean aborted seeds, $\bar{x}=4.7, n=184)$.

Pollen tube growth The number of pollen tubes at the base of the style (PTB) 7 days after pollination was not significantly different among the pollination treatments or floral morphs (two-way ANOvA, $F_{8,139}=0.15, P=0.97$; mean $\mathrm{PTB}$ by pollination
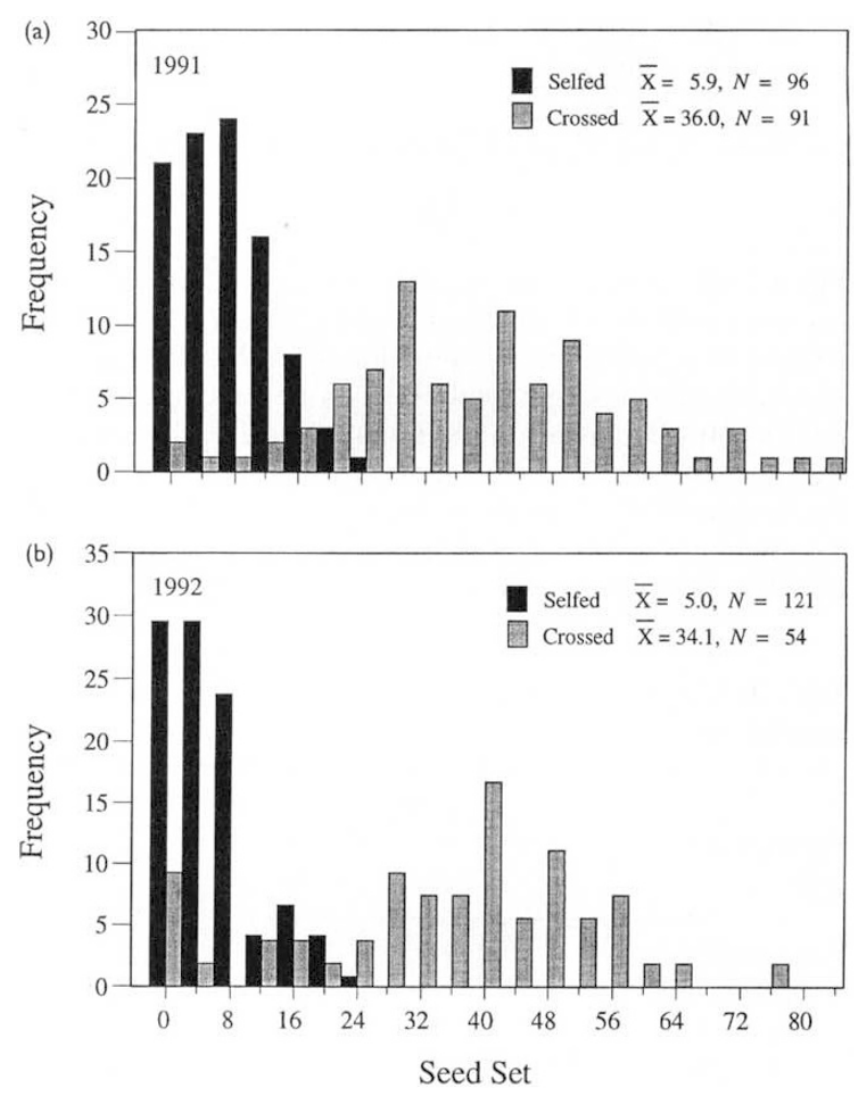

Fig. 3 Seed-set following self- and outcrossed hand pollination of Narcissus triandrus in the glasshouse in two consecutive seasons. For further details of source material and experimental details, see Materials and methods.

treatment: self $\quad \bar{x}=163.2, \quad n=58 ; \quad$ intramorph $\bar{x}=166.3, n=29 ; \quad$ intermorph $\bar{x}=160.8, n=61$; mean PTB by style morph: L morph $\bar{x}=160, n=50$; $M$ morph $\bar{x}=164.5, n=49$; S morph $\bar{x}=164.5$, $n=70$ ). There was a significant positive relationship

(c) The Genetical Society of Great Britain, Heredity, 78, 135-145. 
between the number of pollen tubes at the base of the style and seed-set in cross-pollinated flowers $(r=0.41, P<0.0001, n=89)$, but not self-pollinated flowers $(r=0.15, P=0.025, n=58$; see Table 2$)$.

Prior self-pollination Self-pollen applied $24 \mathrm{~h}$ before outcrossed pollen to stigmas of the three floral morphs of $N$. triandrus resulted in dramatic reductions ( 74 per cent) in seed-set in comparison with outcrossed control flowers $\left(F_{1,56}=77.7, P<0.001\right.$; mean seed-set: outcrossed control $\bar{x}=45.1, n=36$; prior selfing $\bar{x}=11.5, n=36$ ). Other factors in the ANOVA showed no significant relation with seed-set (floral morph, $F_{2,56}=0.02, P=0.98$; flower position, $F_{1,56}=0.87, P=0.36$; plant, $\left.F_{11,56}=1.02, P=0.44\right)$.

\section{Outcrossing frequencies}

Multilocus estimates of outcrossing frequency at the population level averaged 0.77 and ranged from $0.68-0.87$. In all four populations, 95 per cent confidence limits of $t_{\mathrm{m}}$ lay between zero and one, indicating small but significant levels of self-fertilization in each population. Single-locus estimates of outcrossing frequency were lower than multilocus estimates in all populations, but in only two were these differences significant (Table 3 ). No significant differences in multilocus outcrossing frequency were evident between populations following comparisons of bootstrap estimates (all comparisons $P>0.06$ ) and ANova $\left(F_{3,6}=0.71, \quad P=0.58\right)$. Both analyses, however, indicated a significant floral morph effect $\left(F_{2,6}=12.95, P=0.007\right)$. Mean outcrossing frequencies increased with decrease in style length (L morph: 0.70 , SE 0.07 , range $0.58-0.85 ; \mathrm{M}$ morph: 0.82 , SE 0.04 , range $0.76-0.90$; $S$ morph: 0.87 , SE 0.07 , range $0.67-0.98$ ). Specific contrasts between the morphs indicated that the $\mathrm{L}$ morph had a significantly lower frequency of outcrossing than the $\mathrm{S}$ morph ( $t=5.09, P=0.002)$, whereas the differences between the $\mathrm{L}$ and $\mathrm{M}$ morphs $(t=1.62, P=0.16)$ and the $\mathrm{M}$ and $\mathrm{S}$ morphs $(t=1.15, P=0.29)$ were not significantly different overall. From the bootstrap analysis, significant differences in multilocus outcrossing frequency between the floral morphs were evident in only one of the four populations. In population 14 , the $\mathrm{L}$ morph had a significantly lower frequency of outcrossing than the $\mathrm{M}$ and $\mathrm{S}$ morphs.

\section{Discussion}

The major finding of this study is that Narcissus triandrus is genuinely tristylous, with most populations polymorphic for three floral morphs that differ from one another in the sequence in which stigmas and anthers are presented within flowers. Floral measurements and experimental pollinations revealed that $N$. triandrus possesses a distinctive floral syndrome and self-sterility system, both of which are unique among tristylous species. Having resolved the historical controversy concerning the nature of the sexual polymorphisms in this species, we now address how the unusual properties of the tristylous syndrome of $N$. triandrus differ from those of other heterostylous species, how the polymorphisms may function in natural populations and what selective forces are likely to be responsible for their origin in the genus Narcissus.

Table 3 Mating patterns in four populations of Narcissus triandrus from the Iberian peninsula

\begin{tabular}{|c|c|c|c|c|c|c|c|c|}
\hline \multirow[b]{2}{*}{ Population } & \multicolumn{2}{|r|}{$n$} & \multicolumn{2}{|c|}{$t_{\mathrm{m}}$} & \multicolumn{2}{|c|}{$t_{\mathrm{s}}$} & \multicolumn{2}{|c|}{$t_{\mathrm{m}}-t_{\mathrm{s}}$} \\
\hline & Families & Individuals & Mean & SE & Mean & SE & Mean & SE \\
\hline 8 & 52 & 500 & 0.779 & $(0.046)$ & 0.732 & $(0.042)$ & 0.047 & $(0.042)$ \\
\hline 9 & 47 & 472 & 0.866 & $(0.044)$ & 0.795 & $(0.043)$ & 0.071 & $(0.043)$ \\
\hline 10 & 44 & 432 & 0.778 & $(0.061)$ & 0.703 & $(0.057)$ & $0.075^{*}$ & $(0.017)$ \\
\hline 14 & 72 & 733 & 0.685 & $(0.047)$ & 0.589 & $(0.041)$ & $0.096^{*}$ & $(0.015)$ \\
\hline
\end{tabular}

Values presented for each population are the multilocus outcrossing frequency $\left(t_{\mathrm{m}}\right)$, the single-locus outcrossing frequency $\left(t_{\mathrm{s}}\right)$ and the difference between them $\left(t_{\mathrm{m}}-t_{\mathrm{s}}\right)$. Localities for populations are population 8 (Tentudia-1, Badajoz province), population 9 (Tentudia-2, Badajoz province), population 10 (Calera de León-3, Badajoz province) from southern Spain and population 14 (Arenas de San Pedro-2, Avila province) from central Spain. An estimate of the standard error (in parentheses) is based on 1000 bootstraps. Asterisks indicate $t_{\mathrm{m}}-t_{\mathrm{s}}$ significantly greater than zero. 


\section{Floral form and function}

Although three style length groups can easily be identified in $N$. triandrus, there is considerable variation within each of these (Fig. 1). This variation, in conjunction with Bateman's conclusion that anther levels were at a similar height in each floral morph, appears to have led him to question whether the species was tristylous (Bateman, 1952). However, our results clearly indicate that most populations of $N$. triandrus possess three distinct anther levels with some degree of reciprocal correspondence between anther and stigma heights. Lloyd \& Webb (1992) pointed out that the reciprocal herkogamy of heterostylous populations does not necessarily require that the heights of anthers and stigmas match one another precisely, and indeed in many species they do not. Numerical methods for quantifying the degree of sex organ reciprocity in tristylous species indicate that considerable variation exists both within and among species that are widely recognized as tristylous (Lloyd et al., 1990; Eckert \& Barrett, 1994). Nevertheless, in a survey of floral precision and reciprocity in 30 populations of 13 tristylous species, it was found that $N$. triandrus had one of the most distinct patterns (see Fig. 12 in Eckert \& Barrett, 1994). This occurred primarily because of the 'anomalous' positioning of anthers and stigmas in the L morph.

Our surveys of floral morph frequencies in natural populations indicated two clear patterns. First, the $\mathrm{L}$ morph predominated in most populations, regardless of whether they were trimorphic or dimorphic for style length. Secondly, all populations that were dimorphic were missing the $M$ morph. These patterns are quite different from other tristylous species that have been examined. In tristylous species with heteromorphic incompatibility, a 1:1:1 morph ratio is expected in large populations at equilibrium because of frequency-dependent mating. Such a mating pattern is assured in most tristylous species, because only intermorph matings result in full seed-set. However, in Narcissus, because floral morphology is not genetically linked to self-sterility, morph frequencies will be determined largely by features of floral morphology that determine the fitness of morphs as pollen and seed parents.

Reproductive success in the floral morphs of $N$. triandrus is likely to depend critically on the pollination biology of populations and, particularly, the patterns of pollen transfer. A recent phenotypic selection model to account for the maintenance of stigma-height polymorphisms in dimorphic Narcissus species demonstrated that equilibrium morph ratios are highly sensitive to asymmetries in the amount of pollen transferred between morphs (Barrett et al., 1996). Results from the model suggest that the predominance of the $\mathrm{L}$ morph of $N$. triandrus is most probably associated with variation in the transfer efficiency of pollen between anthers and stigmas, resulting in morph-specific differences in male fertility. The 'anomalous' anther positions in the $\mathrm{L}$ morph may provide this morph with an advantage in both intermorph and intramorph matings compared with the other two morphs.

The 12 dimorphic populations of $N$. triandrus that were missing the $M$ morph occurred scattered throughout central and northern Portugal and Atlantic Spain. Tristylous populations in this region were characterized by having a much lower frequency of the $M$ morph than was found elsewhere in the distribution (see Table 3 in Barrett et al., 1996). This pattern suggests that ecological conditions in the northern part of the range of $N$. triandrus may often be unsuitable for the maintenance of floral trimorphism. In this regard, it is worth noting that disjunct populations on Iles de Glénans, a small group of islands off the Brittany coast of France, are also dimorphic for the $\mathrm{L}$ and $\mathrm{S}$ morphs (Fernandes, 1965).

\section{Pollen-pistil interactions and the nature of self- sterility}

Controlled pollinations enabled rejection of the hypothesis that $N$. triandrus possesses a heteromorphic incompatibility system. All crosses resulted in seed-set, irrespective of which anther level was used or whether pollinations were intramorph or intermorph. Hence, unlike other self-incompatible tristylous species, in $N$. triandrus the Darwinian terms legitimate and illegitimate do not correspond to compatible and incompatible matings respectively. Bateman (1954), working with a small sample of plants, also demonstrated that intramorph crosses were compatible. The presence of an apparently multiallelic form of self-sterility, rather than the more familiar diallelic incompatibility, has probably also been a major factor preventing earlier workers from accepting $N$. triandrus as a genuinely heterostylous species. However, if a strictly morphological definition of heterostyly is adopted, as is done here, the occurrence of tristyly and a putative incompatibility system involving multiple mating groups is of less concern.

The association between heterostyly and intramorph compatibility in $N$. triandrus, although unusual, is not in fact unique among heterostylous 
groups (reviewed in Barrett \& Cruzan, 1994). In distylous Anchusa spp., for example, self-sterility and floral dimorphism are also not associated (Dulberger, 1970; Schou \& Philipp, 1984). The reproductive system of $A$. officinalis, in particular, bears a strong resemblance to that found in Narcissus. In this species, anther heights are much less differentiated than stigma height, and ancillary polymorphisms of pollen and stigmas are only weakly developed. The $\mathrm{L}$ morph predominates in most populations of $A$. officinalis, and the species exhibits a late-acting selfsterility system, an unusual condition in heterostylous plants. Finally, cross-pollinations in $A$. officinalis result in a wide range of seed-set values, a pattern also found in $N$. triandrus (see below). These similarities appear to involve a distinctive syndrome and suggest that these two unrelated taxa may possess similar genetic systems governing the evolution and maintenance of heterostyly.

The genetic and physiological basis of the selfsterility system in $N$. triandrus is unknown. Two reproductive mechanisms acting alone or in combination could result in reduced seed-set of selfs compared with outcrosses. Self-incompatibility similar to the homomorphic type (possibly under quantitative genetic control) would seem likely in $N$. triandrus, as the patterns of seed-set observed could be obtained from this type of system. Alternatively, early-acting inbreeding depression could also give rise to differences in seed-set between self and outcrosses and could, therefore, potentially play some role. Unfortunately, distinguishing between these two mechanisms, although conceptually straightforward, can be a difficult task, particularly when both are involved in determining the fertility of crosses and selfs (Seavey \& Bawa, 1986).

The most striking aspect of the seed-set data from cross-pollinations was the wide range of values that was obtained (Fig. 3). This variation was found in both years and was uncorrelated with pollination type or floral morph. The relative contributions of genetic and environmental factors to this variation is not known, but it is possible that the fertility variation is associated with the relatedness of individuals used in the crossing programme. Populations of $N$. triandrus are spatially structured and composed of colonies of potentially related individuals. High seed-set values could arise from crosses among unrelated individuals, with those among closely related individuals giving lower levels of seed-set. Such correlations between the degree of relatedness of individuals and the fertility of crosses have been demonstrated elsewhere by Krebs \& Hancock (1990) and Seavey \& Carter (1994).
A critical issue in determining the mechanisms of self-rejection and factors responsible for wide variation in seed-set observed in crosses is whether the proximate controls on fertility in $N$. triandrus are exerted pre- or postzygotically. Bateman (1954, p. 24) stated that in $N$. triandrus 'pollen tubes grow quite as fast on selfing as on crossing, for the full length of the style. The incompatibility must be lateacting, somewhere in the ovary, and perhaps even after fertilization'. Similar observations were also made by Dulberger (1964) in her studies of dimorphic $N$. tazetta. Our own observations of pollen tube growth and seed-set in $N$. triandrus are consistent with Bateman's suggestion that the species possesses a late-acting ovarian self-sterility system. However, further work is needed to determine whether self-sterility in Narcissus spp. operates preor postzygotically and whether inbreeding effects ałso play some role.

Species with late-acting ovarian self-sterility are susceptible to reductions in fertility owing to the prior application of self pollen to cross-pollinated stigmas (e.g. Waser \& Price, 1991; Seavey \& Carter, 1994). We also demonstrated this effect using a pollen chase experiment in $N$. triandrus. Although the specific mechanism(s) responsible for seed-set reduction require additional work, several aspects of the floral biology of the species suggest that prior self-pollination could have potentially important ecological and evolutionary consequences. Flowers of $N$. triandrus are quite long-lived, retaining some reproductive function for up to 1 week. As pollinator visitation to $N$. triandrus populations during early spring is often infrequent (S. C. H. Barrett, personal observation), it seems likely that delays in the receipt of cross pollen may often occur. If self pollen is deposited on stigmas before the arrival of outcross pollen, self pollen tubes in the ovary could potentially render ovules nonfunctional leading to reduced fertility. This phenomenon has been termed ovule discounting and its effect on the evolution of stigmaheight dimorphisms in Narcissus has been examined theoretically (Barrett et al., 1996). Further empirical work is needed, however, to determine whether in natural populations of $N$. triandrus the schedule and amount of self and outcross pollen deposited on stigmas results in significant ovule discounting.

\section{Mating patterns and the maintenance of tristyly}

Estimates of mating patterns in four populations of $N$. triandrus using allozyme markers indicated that the species was primarily outcrossing, averaging 0.77 . 
Small amounts of selfing were, however, detected in each population. The occurrence of some selfing probably reflects the 'leaky' nature of the selfsterility system in $N$. triandrus, as revealed by the results of self-pollinations in the crossing programme. Single-locus estimates of outcrossing were significantly lower than multilocus estimates in two populations, providing evidence for the occurrence of biparental inbreeding. The strong spatial structure of $N$. triandrus populations (S.C.H. Barrett, personal observation), in conjunction with limited seed dispersal because of the diminutive stature of plants, probably enhances opportunities for mating among related individuals.

It was not possible to estimate the degree of disassortative mating in populations of $N$. triandrus and evaluate the effectiveness of tristyly in promoting intermorph mating. Models of the maintenance of tristyly under various modes of inheritance indicate that, as long as outcrossed matings include some component that is disassortative, the polymorphism will be maintained by frequency-dependent selection (Charlesworth, 1979). All populations of N. triandrus surveyed were polymorphic, with the majority containing all three morphs. This indicates that significant levels of disassortative mating must occur in most populations and implies that floral trimorphism functioning in the absence of trimorphic incompatibility can by itself promote intermorph mating. Similar conclusions on the efficacy of morphological tristyly in promoting disassortative mating were reached by Kohn \& Barrett (1992) following experimental studies of self-compatible, tristylous Eichhornia paniculata.

The isolated occurrence of tristyly in a single species in the genus Narcissus (see Barrett et al., 1996) strongly suggests that its origin was a rare event. Elsewhere in the monocotyledons, heterostyly occurs in only three genera - Eichhornia and Pontederia of the Pontederiaceae and Nivenia of the Iridaceae - families that are unrelated to the Amaryllidaceae (Graham \& Barrett, 1995). As most Narcissus species appear to be self-sterile (Barrett et al., 1996), it seems probable that the evolution of floral trimorphism occurred in ancestors that were largely outcrossing. If this is true, the selective forces responsible for establishment of the morphological polymorphisms probably involved selection on the male component of fitness and not factors related to rates of selfing and inbreeding depression in ancestral populations. The evolution of tristyly in $N$. triandrus most likely arose as an adaptation improving the transfer of pollen between individuals.

\section{Acknowledgements}

We thank Fanny Strumas for technical assistance and Deborah Charlesworth, Rivka Dulberger, Christopher Eckert, Lawrence Harder and Tammy Sage for advice. This work was funded by research grants from the Natural Sciences and Engineering Research Council of Canada to S.C.H.B.

\section{References}

BARRETT, S. C. H. 1988. The evolution, maintenance, and loss of self-incompatibility systems. In: Lovett Doust, J. and Lovett Doust, L. (eds) Plant Reproductive Ecology. Patterns and Strategies, pp. 98-124. Oxford University Press, New York.

BARRETT, S. C. H. 1993. The evolutionary biology of tristyly. Oxford Surveys in Evolutionary Biology, 9, 283-286.

BARRETT, S. C. H. AND CRUZAN, M. B. 1994. Incompatibility in heterostylous plants. In: Williams, E. G., Knox, R. B. and Clark, A. E. (eds) Genetic Control of Incompatibility and Reproductive Development in Flowering Plants, pp. 189-219. Kluwer Academic Publishers, Dordrecht, The Netherlands.

BARRETT, S. C. H., LlOYD, D. G. AND ARROYO, J. 1996. Stylar polymorphisms and the evolution of heterostyly in Narcissus (Amaryllidaceae). In: Lloyd, D. G. and Barrett, S. C. H. (eds) Floral Biology: Studies on Floral Evolution in Animal-Pollinated Plants, pp. 339-376. Chapman \& Hall, New York.

BATEMAN, A. J. 1952. Trimorphism and self-incompatibility in Narcissus. Nature, 170, 496-497.

Bateman, A. J. 1954. The genetics of Narcissus. I. Sterility. Daffodil and Tulip Year Book, 19, 23-29. Royal Horticultural Society, London.

Blanchard, J. w. 1990. Narcissus: $A$ Guide to Wild Daffodils. Alpine Garden Society, Woking, Surrey, U.K.

CHARLESWORTH, D. 1979. The evolution and breakdown of tristyly. Evolution, 33, 486-498.

DULBERGER, R. 1964. Flower dimorphism and self-incompatibility in Narcissus tazetta L. Evolution, 18, 361-363.

DUlberger, R. 1970. Floral dimorphism in Anchusa hybrida Ten. Isr. J. Bot., 19, 37-41.

ECKERT, C. G. AND BARRETT, s. C. H. 1994. Tristyly, selfcompatibility and floral variation in Decodon verticillatus (Lythraceae). Biol. J. Linn. Soc., 53, 1-30.

FERNANDES, A. 1935. Remarque sur l'hétérostylie de Narcissus triandrus et de $N$. reflexus. Bol. Soc. Brot., Sér. $2,10,5-15$.

FERNANDES, A. 1965. Contribution à la connaissance de la génétique de l'hétérostylie chez le genre Narcissus L. II. L'hétérostylie chez quelques populations de $N$. triandrus var. cernuus et $N$. triandrus var concolor. Genét. Ibérica, 17, 215-239.

Graham, s. W. AND BarretT, s. C. H. 1995. Phylogenetic systematics of Pontederiales: Implications for breedingsystem evolution. In: Rudall, P. J., Cribb, P. J., Cutler, 
D. F. and Humphries, C. J. (eds) Monocotyledons: Systematics and Evolution, pp. 415-441. Royal Botanic Gardens, Kew.

HENRIQUES, J. A. 1887. Observações sobre algumas especies de Narcissus, encontrados em Portugal. Bol. Soc. Brot., 5, 168-174.

KOHN, J. R. AND BARRETT, S. C. H. 1992. Experimental studies on the functional significance of heterostyly. Evolution, 46, 43-55.

KREBS, S. L. AND HANCOCK, J. F. 1990. Early acting inbreeding depression and reproductive success in the highbush blueberry Vaccinium corymbosum (Ericaceae). Theor. Appl. Gen., 79, 825-832.

LEMMENS, R. H. M. J. 1989. Heterostyly. In: Jongkind, C. C. H. and Lemmens, R. H. M. J. (eds) The Connaraceae, a Taxonomic Study with Emphasis on Africa, pp. 56-69. Agricultural University of Wageningen Papers, Wageningen, The Netherlands.

LLOYD, D. G. AND WEBB, C. J. 1992. The evolution of heterostyly. In: Barrett, S. C. H. (ed.) Evolution and Function of Heterostyly, pp. 151-178. Springer-Verlag, Berlin.

LLOYD, D. G., WEBB, C. J. AND DULBERGER, R. 1990. Heterostyly in species of Narcissus (Amaryllidaceae) and Hugonia (Linaceae) and other disputed cases. Pl. Syst. Evol., 172, 215-227.

NETTANCOURT, D. DE 1977. Incompatibility in Angiosperms. Springer-Verlag, Berlin.
RITLAND, K. 1990. A series of FORTRAN computer programs for estimating plant mating systems. J. Hered., 81, 235-237.

SAS INSTITUTE INC. 1988. SAS/STAT ${ }^{\circledR}$ User's Guide, Release 6.03 edn. SAS Institute Inc., Cary, NC.

SCHOU, O. AND PHILIPP, M. 1984. An unusual heteromorphic incompatibility system. III. On the genetic control of distyly and self-incompatibility in Anchusa officinalis L. Theor. Appl. Genet., 68, 139-144.

SEAVEY, S. R. AND BAWA, K. S. 1986. Late-acting selfincompatibility in angiosperms. Bot. Rev., 52, 195-219.

SEAVEY, S. R. AND CARTER, S. K. 1994. Self-sterility in Epilobium obcordatum (Onagraceae). Am. J. Bot., 81, 331-338.

SIDÁK, z. 1967. Rectangular confidence regions for the means of multivariate normal distributions. J. Am. Stat. Ass., 62, 626-633.

THOMPSON, J. D., PAILlER, T., STRASBERG, D. AND MAN1CACCI, D. 1996. Tristyly in the endangered Mascarene Island endemic Hugonia serrata (Linaceae). Am. J. Bot., 83, 1160-1168.

WASER, N. M. AND PRICE, M. v. 1991. Reproductive costs of self-pollination in Ipomopsis aggregata (Polemoniaceae): are ovules usurped? Am. J. Bot., 78, 1036-1043.

ZAVADA, M. S. AND LOWREY, T. K. 1995. Floral heteromorphism in Dais cotinifolia L. (Thymelaeaceae): a possible case of heterostyly. Bull. Mus. Natl. Hist. Paris Ser. 17 Section B, Adansonia nos. 1-2, 11-20. 